\title{
Examination of appropriate observation time and correction of vegetation index for drone-based crop monitoring
}

\author{
Akira HAMA $^{\mathrm{a}, \dagger}$, Kei TANAKA ${ }^{\mathrm{b}}$, Bin $\mathrm{CHEN}^{\mathrm{c}}$ and Akihiko KONDOH ${ }^{\mathrm{d}}$ \\ ${ }^{a}$ Graduate School Course of Horticultural Science, Chiba University, 648, Matsudo, Matsudo-shi, Chiba 271-8510, Japan \\ b Japan Map Center, 4-9-6 Aobadai, Meguro-Ku, Tokyo 153-8522, Japan \\ ${ }^{c}$ DJI Japan K.K., Shinagawa Season Terrace 11F, 1-2-70 Konan, Minato-Ku, Tokyo 108-0075, Japan \\ ${ }^{\mathrm{d}}$ Center for Environmental Remote Sensing, Chiba University, 1-33 Yayoi-Cho, Inage-Ku, Chiba, Chiba 263-8522, Japan
}

\begin{abstract}
Use of information and communication technologies, as well as robotics, routinely saves labor and refines agricultural tasks; thus, innovative "smart farming" to maintain and enhance the quality of crops can improve the sustainability of agriculture. When managing crop growth using remote-sensing drones, the normalized difference vegetation index (NDVI) — used to assess growth—typically changes depending on sunlight conditions. In this study we have attempted to develop an empirical correction to correct for differences in sunlight conditions in drone NDVI images of paddy rice. Based on observations using a field sensor installed in a paddy field, and considering the effects of morning dew, we determined that 10:00 AM is the most appropriate time for NDVI observations in paddy rice, when the morning dew has largely evaporated. This observation time differs from that used in the radiative transmission models described in previous studies. In the drone observations, sections with lower NDVI were more strongly affected by solar altitude, and thus by time of day. Therefore, we found that when correcting NDVI according to sunlight conditions, it is necessary to adjust the correction parameters depending on the NDVI values. Based on the aforementioned results, we corrected the drone-observed NDVI and succeeded in mitigating the decline in NDVI value associated with changes in sunlight conditions, in terms of both NDVI values and NDVI images, within plots established in the experimental field.

Key words: Drone RS, NDVI, Smart farming, Sunlight condition
\end{abstract}

\section{Introduction}

Changes over recent years in the global climate, typically warming, have significantly changed the environments in which agricultural crops are grown. These changes typically diminish crop production and are predicted to become more widespread in the future (IPCC, 2014). Improving agricultural sustainability is a global challenge, and the most important mission in different production regions will be to develop innovative methods of cultivation management to cope with changes in the growth environment.

In the 20 years leading up to 2015, the agricultural workforce in Japan shrank by approximately 50\%, and the area of abandoned fields and rice paddies now exceeds 400000 ha (MAFF, 2016). Furthermore, the remaining workforce is aging considerably, with 66.3 years being the current average age of agricultural workers (MAFF, 2016). Consequently, it is necessary not only to secure crop quality and yield, but also to protect the sustainability of Japan's agriculture. Preserving and managing future agriculture and farmland is of immediate importance, with

Received; November 30, 2020

Accepted; April 30, 2021

†Corresponding author: a.hama@chiba-u.jp

DOI: 10.2480 /agrmet.D-20-00047

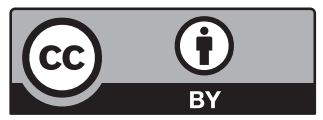

(C) Author (s) 2021.

This is an open access article under the CC BY 4.0 license. implications for the sustainability of society as a whole.

Given that robotics and information/communication technologies are now routinely used to save labor and refine agricultural tasks, maintaining and improving the quality of crops with innovative "smart farming" could significantly enhance the sustainability of agriculture. Smart farming activities may potentially save labor and lighten agricultural workloads, as well as attract new agricultural workers and allow existing farmers to improve their technical abilities in cultivation (Inoue and Yokoyama, 2017). In this regard, the importance of remote sensing (RS) technology—contactless sensing and image analysis that can measure and estimate farmland targets-has become widely recognized (MAFF, 2019).

RS developed as an information-processing and analysis method for observational data from artificial satellites; numerous studies have employed RS data for vegetation monitoring. Among the potential applications of RS-based vegetation observations, the monitoring of agricultural croplands presents practical challenges regarding image analysis and information processing technology (Saito et al., 2017). With RS, visible to near-infrared spectrum information can be used to measure and estimate plant structures of above-ground vegetation, such as crop biomass and leaf area index (LAI), as well as the nutrient content (chlorophyll, nitrogen, and phosphorus) of crop plants (Inoue and Yokoyama, 2017; Mee et al., 2017). The use of satellite data for farming guidance, such as optimizing harvest timing and fertilizer application (Sakaiya et al., 2016), is an example of the practical use of RS in agriculture. 
However, RS by satellites has certain practical limitations. For example, using optical satellite imagery, the ground surface is generally not observable in the presence of clouds, and because of observation frequency (the specific number of days between images of the same location), it is difficult to observe crops at the right time. By contrast, low-altitude RS using drones (drone RS) delivers a highly maneuverable platform that can make observations at the right time (Hama et al., 2020b).

With regard to RS using drones, we have previously shown that the normalized difference vegetation index (NDVI) can be used as an explanatory variable to estimate such paddy rice growth parameters (plant structures) as plant height and LAI (e.g., Hama et al., 2016; 2018). In recent years, other groups have similarly used the vegetation index obtained by drones to estimate crop yield (e.g., Zhou et al., 2017; Herrmann et al., 2020). Studies have also been conducted to assess the development of detailed fertilization standards by using vegetation metrics based on the relationship between these indices and crop growth (e.g., Guan et al., 2019; Mochizuki et al., 2020).

There are, however, concerns that sunlight conditions may affect the results of vegetation indices obtained using drone RS, depending on weather conditions and timing. Accordingly, as drones are increasingly making low-altitude RS easier and more effective, the influence of sunlight conditions on the quality of collected data warrants further consideration. In the aforementioned studies (Hama et al., 2016; Zhou et al., 2017), the observation time was uniformly set between 10:00 and 14:00. However, in practical application, it is not always possible to set the observational time uniformly when monitoring agricultural sites. In practice, vegetation index values do not remain fixed throughout the day, given that as solar altitude (the angle of the sun above the horizon) increases, vegetation index values are shown to decrease (Cogliati et al., 2015; Rahman et al., 2015). Furthermore, this effect is also influenced by the weather, with solar altitude affecting the vegetation index more on clear days-when a greater proportion of the direct components of solar radiation reach lower altitudes-and a smaller effect on cloudy days when the dispersion of sunlight components is greater (Ishihara et al., 2015; Hashimoto et al., 2019). In addition, vegetation density also has an effect, with areas of greater density being found to be affected to a lesser extent by solar altitude (Ishihara et al., 2015). The effect of sunlight conditions on the NDVI can be explained thus: the higher the solar altitude, the greater is the proportion of incoming light reaching the ground surface beneath the vegetation layer; under these circumstances, the ground has a greater influence on the reflected light being observed from above (Ishihara et al., 2015). The diffusion of incoming sunlight is greater on cloudy days, and the influence of sunlight conditions is reduced at higher vegetation densities. Moreover, these effects of sunlight conditions are apparent even when converting observational data to reflectance values.

As previously mentioned, it is essential to correct for these effects of sunlight conditions when using vegetation indices to estimate growth, and when using RS data as a basis for determining growth management tasks such as fertilization control. One previous study applied corrections based on estimating the LAI from machine-learned or multiple regression models that use the solar zenith angle, ratio of diffuse solar radiation, canopy reflectance, understory reflectance, or vegetation index as explanatory variables (Hashimoto et al., 2020). This method has obtained sound results; however, it does not mitigate the effects of sunlight conditions on the vegetation index itself.

Furthermore, when using drone RS, it is difficult to capture accurate images of the reflectance and to utilize spectral data; thus, it is preferable to use normalized indices, including NDVI, which apply the same wavelength bands in the numerator and denominator (section 2.1 below). When using established vegetation indices such as the enhanced vegetation index (EVI) (Liu and Huete, 1995), there is a greater effect (compared to NDVI) attributable to irregularities in brightness due to plant shadows, which in turn increases the influence of factors that are unrelated to vegetation status (Matsushita et al., 2007). In practice, given that the use of a normalized vegetation index is assumed, methods for correcting the vegetation index itself are also considered, even when no method is used to correct for the individual wavelength bands.

Therefore, in this study, we focused primarily on correcting for sunlight conditions in the NDVI drone-captured images of paddy rice. Specifically, we sought to develop an empirical correction formula in which the amount of correction corresponds to variations in growth. With practical use in mind, we strived to produce a corrective method that is simple and requires as few parameters as possible to make the corrections.

\section{Materials and Methods}

To achieve the stated objectives, the present study was conducted in 2020 according to the following process.

1. Analyze the appropriate time during the day for observations and set standard values for making corrections (see section 2.1 below).

2. Monitor paddy rice when close to the period of fertilization and when close to the heading stage; develop an empirical formula to correct NDVI changes contingent upon changes in sunlight conditions (see section 2.2).

\subsection{Study sites and field observation equipment}

For the purposes of the present study, we used a paddy field located in Sakado, Saitama Prefecture $\left(35^{\circ} 58^{\prime} \mathrm{N}, 139^{\circ} 23^{\prime} \mathrm{E}\right)$ as the experimental field (Fig. 1). A ground control point (GCP) was installed at each of the four corners of the field, and the position of each was determined through measurements made with a total station theodolite (Ushikata Co. TEO-Ray). "Koshihikari” (Oryza sativa L. cv. Koshihikari) rice was transplanted on May $22^{\text {nd }}$; the panicle formation stage was on July $11^{\text {th }}$, the heading stage was on August $5^{\text {th }}$, and the crop was harvested on September $10^{\text {th }}$. To observe differences in NDVI results due to variations in growth, we established two $1 \mathrm{~m} \times 1 \mathrm{~m}$ plots for rice-exhibiting dense, moderate, and sparse growth, respectively-totaling six plots. We also installed a pyranometer (Climatec CHF-SR05-DA1) and leaf wetness sensor (Climatec C-LWS) in the experimental field. The observation interval was set at $10 \mathrm{~min}$. 


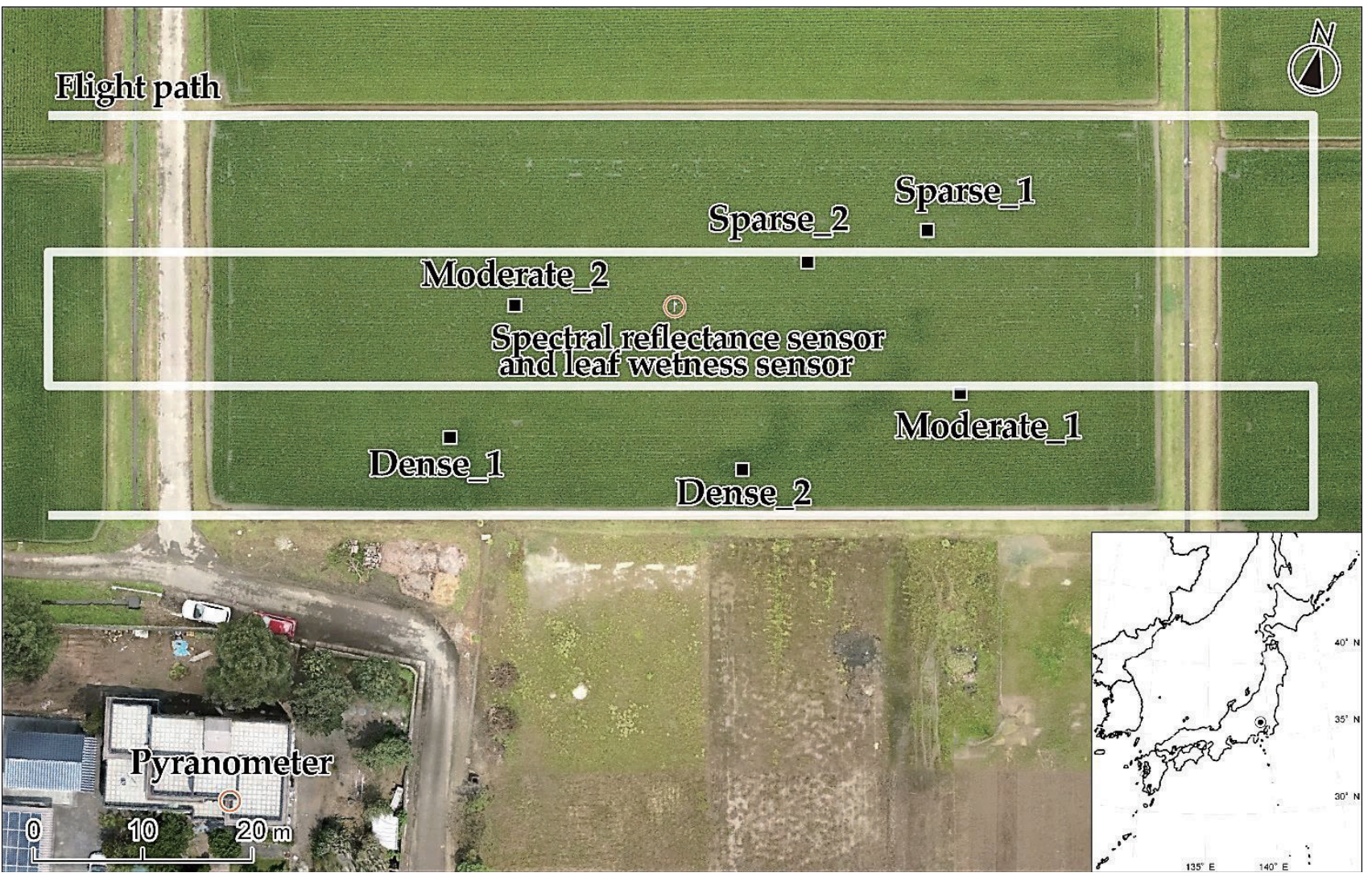

Fig. 1. The Saitama experimental field: Black square in the field indicate plots. A spectral reflectance sensor and leaf wetness sensor were installed in the centre of the field. The line denotes the flight path of the drone when the sun was hidden by the clouds. When the sun blazed down, the GS Pro automatically recommended flight path was used.

To determine an appropriate time for daily observations, we installed field-use spectral reflectance sensors (Decagon Devices SRS-Nr Field Stops Sensor, SRS-Ni Hemispherical Sensor) in the center of the field, adjusted to a height of $1.5 \mathrm{~m}$ from the ground surface (Picture 1). By attaching two sensors that can detect near-infrared $(810 \pm 2 \mathrm{~nm})$ and red $(650 \pm 2 \mathrm{~nm})$ wavelength bands, one facing upward and the other downward, the sensor was able to continuously detect the reflectance-based NDVI (Formula 1).

$$
N D V I_{\text {field }}=\left(N I R_{\text {field }}-\operatorname{Red}_{\text {field }}\right) /\left(N I R_{\text {field }}+\operatorname{Red}_{\text {field }}\right) \text {, }
$$

where $N D V I_{\text {field }}$ is the field sensor-based NDVI, and NIR field and $\operatorname{Red}_{\text {field }}$ are the field-sensor-based near-infrared (NIR) band and red band reflectance, respectively. The observation interval was set at $10 \mathrm{~min}$, and observations were made from the end of planting until harvest. As NDVI represents paddy rice growth parameters (plant structures), large and variable day-to-day fluctuations are undesirable. Thus, the appropriate observation time will be when the NDVI time-series representation is smooth. To examine the appropriate observation time, a curve smoothed by locally weighted scatterplot smoothing (LOWESS) was created of $\mathrm{NDVI}_{\text {field }}$ against observation time. Then, the smoothness of the time-series changes was evaluated as the coefficient of determination $\left(\mathrm{R}^{2}\right)$ analysis of the LOWESS curve against the observed $\mathrm{NDVI}_{\text {field. }}$.

\subsection{Drone image acquisition}

In this study, we used a DJI Phantom 4 Multispectral (P4M) drone, which can be used to detect five wavelengths: blue (450 $\pm 16 \mathrm{~nm})$, green $(560 \pm 16 \mathrm{~nm})$, red $(650 \pm 16 \mathrm{~nm})$, red-edge $(730$ $\pm 16 \mathrm{~nm})$, and near-infrared $(840 \pm 26 \mathrm{~nm})$. It is also equipped with a spectral sunlight sensor located at the top of the drone, which records solar irradiance. This solar irradiance was used in converting the digital number (DN) to signal values, as described below. Aerial photography was conducted using P4M at roughly one-hour intervals on July $22^{\text {nd }}$ and August $5^{\text {th }}, 2020$. July $22^{\text {nd }}$ (between the panicle formation stage and the heading stage) was an important time for observing paddy rice growth and using the results to adjust fertilization regimes. August $5^{\text {th }}$ (heading stage) was important for estimating the yield or protein content of brown rice by using the drone-based observation data (Hama et al., 2020a; 2020b). We developed a correction formula by using the data obtained on July $22^{\text {nd }}$, and verified the formula using the data from both July $22^{\text {nd }}$ and August $5^{\text {th }}$. The weather on July $22^{\text {nd }}$ was clear with occasional clouds, and was generally clear on August $5^{\text {th }}$. DJI GS PRO iOS software was used to fly the P4M at an altitude of $50 \mathrm{~m}$ above the ground, with the flight-path adjusted for $90 \%$ image-height overlap and $70 \%$ image-width overlap. The camera was set perpendicularly, and photographs were taken at two-second intervals. Figure 1 shows the flight path of the drone when the sun was hidden by clouds. When the sun was unobscured, the GS PRO automatically recommended 


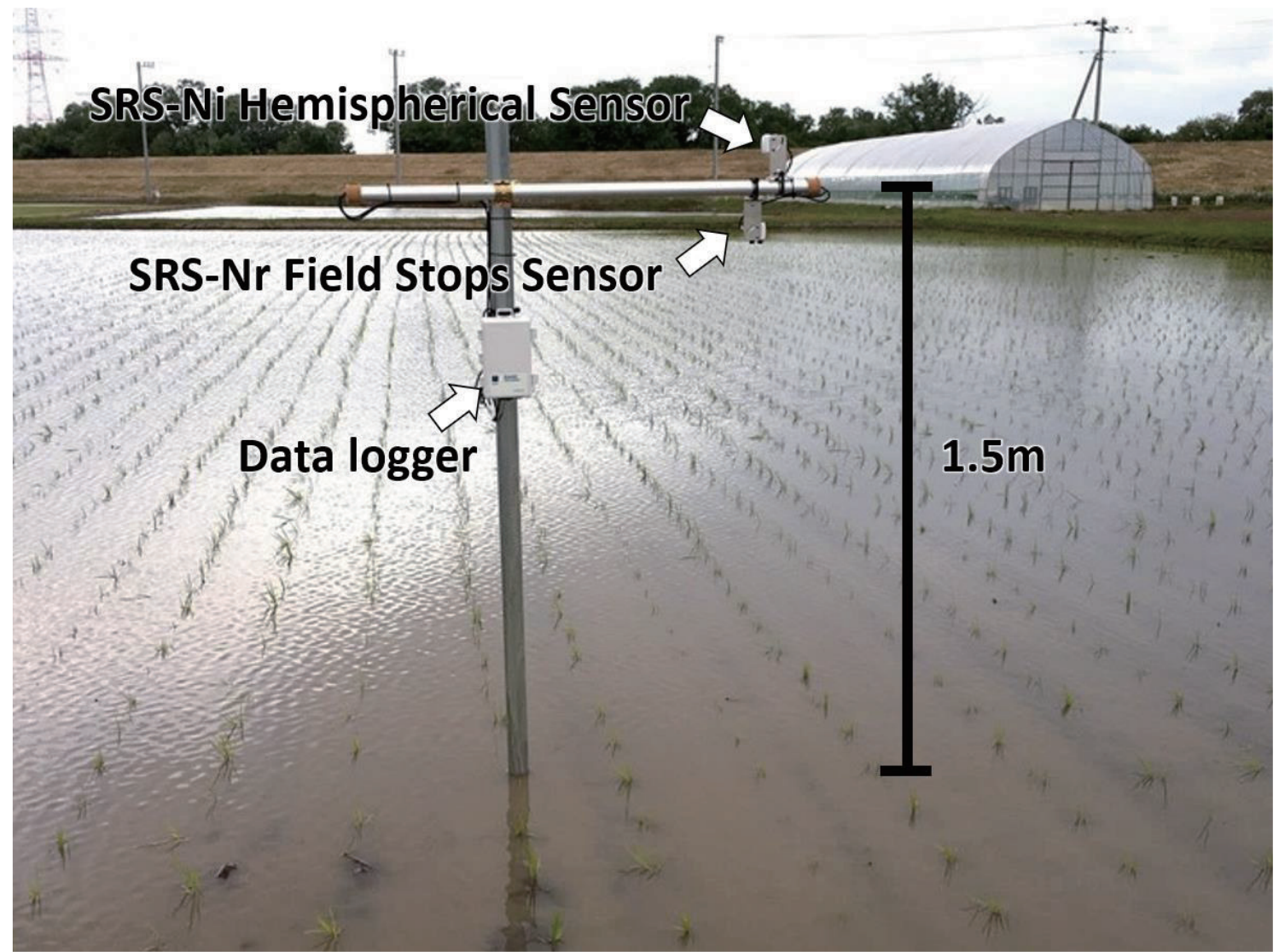

Picture 1. The spectral reflectance sensor installed in the experimental field. SRS-Ni hemispherical sensor was facing upward and SRS-Nr field stops sensor was facing downward.

a flight path. At $50 \mathrm{~m}$ altitude, the ground resolution of the captured images was approximately $2.6 \mathrm{~cm}$.

\subsection{Data and analysis}

\subsubsection{Preprocessing of drone imagery}

Although each of the images captured using the P4M had a recorded $\mathrm{DN}$, the calculated value of the vegetation index varied according to different exposure times and different target brightness. Thus, it was necessary to convert the DN values to spectral reflectance values or to image data that would consistently represent the reflectance. The P4 Multispectral Image Processing Guide (DJI, 2020) for the P4M explains the process of converting $\mathrm{DN}$ data to consistent signal values that account for the effects of exposure time, gain, solar irradiance, and so on. This pixel-value conversion can be performed automatically using Structure-from-Motion/Multi-view Stereo (SfM-MVS) software such as DJI Terra and Pix4Dmapper (Pix4D, Lausanne, Switzerland), enabling the creation of a single orthomosaic from multiple images captured by the drone.

However, as we used Agisoft Metashape Professional (v1.6.0; Agisoft LLC, Russia) in the present study, we were unable to automatically convert pixel values. Thus, following the P4 Multispectral Image Processing Guide, we converted the DN values to signal values (see the P4 Multispectral Image Processing Guide for details on the conversion method).

\subsubsection{Image processing}

We used the images that had been converted into signal values to create an orthomosaic by using Agisoft Metashape Professional for each wavelength band. By subjecting the orthomosaic to analysis by using the open-source Geographic Information System (GIS) software QGIS (www.qgis.org), we calculated the NDVI and the average values within the six evaluated plots. NDVI was calculated using the following formula:

$$
N D V I_{P 4 M}=\left(N I R_{P 4 M}-R_{P 4 M}\right) /\left(N I R_{P 4 M}+R_{P 4 M}\right),
$$

where $N D V I_{P 4 M}, N I R_{P 4 M}$, and $R_{P 4 M}$ are the P4M-based NDVI, NIR, and red signal values, respectively.

\subsubsection{Correction of the vegetation index}

We used the following process for NDVI correction, taking into account sunlight conditions.

Initially, we separated the global solar radiation at the time of observation into direct and diffuse components, based on Inanuma and Takeda (2002) method (Formulae 3 to 7).

$$
\begin{aligned}
& \theta=H_{D} \pi / 180 \\
& K t=I_{G} / Q \\
& C_{R i}=0.876+0.623 K t-4.854 K t^{2}+3.155 K t^{3}+0.25 \sin \theta \\
& I_{S}=I_{G} C_{R i} \\
& I_{D}=I_{G}-I_{S}
\end{aligned}
$$

Here, $\theta$ is the solar altitude at the time of observation (radians), $H_{D}$ is the solar altitude at the time of observation $\left(^{\circ}\right), K t$ is the 
clearness index, $I_{G}$ is global solar radiation $\left(\mathrm{W} / \mathrm{m}^{2}\right), I_{S}$ diffuse solar radiation $\left(\mathrm{W} / \mathrm{m}^{2}\right), I_{D}$ is the direct solar radiation $\left(\mathrm{W} / \mathrm{m}^{2}\right), Q$ is the global solar radiation outside the atmosphere $\left(\mathrm{W} / \mathrm{m}^{2}\right)$, and $C_{R i}$ is the cloud ratio.

Next, we performed NDVI corrections according to the following procedure (Formulae 8 to 11 ).

$$
\begin{aligned}
& C f=\left(H_{D}-H_{o}\right) I_{D} / I_{G} \\
& N D V I_{s t d} / N D V I_{o b s}=S C f+1 \\
& S=a N D V I_{s t d}+b \\
& N D V I_{s t d}=N D V I_{o b s}(1+b C f) /\left(1-a N D V I_{o b s} C f\right)
\end{aligned}
$$

Here, $C f$ and $S$ are the NDVI correction variables, $H_{D}$ is the solar altitude at the time of observation $\left({ }^{\circ}\right), H_{o}$ is the assumed standard solar altitude $\left({ }^{\circ}\right), a$ is the slope, $b$ is the intercept, $N D V I_{\text {std }}$ is the NDVI at the assumed standard time, and $N D V I_{\text {obs }}$ is the NDVI at the time of observation. The assumed standard solar altitude is the solar altitude at the appropriate time for observing NDVI. In Formula (8), the correction parameter values increase as the solar altitude increases beyond the assumed standard solar altitude. The effects of weather are also considered in Formula (8) and structured such that the correction factor increases with increasing amounts of direct solar radiation. Next, using Formula (9), we obtain the variable $S$ for changing the amount of correction depending on the NDVI values for the six plots established within the experimental field. (See section 3.3 below for further explanation of the variable $S$.) This is based on regression analysis using the NDVI rate of variability of each observation time relative to the assumed standard time as the objective variable and $C f$ as the explanatory variable. Next, using Formula (10), we determine the parameters $a$ and $b$, based on regression analysis using $S$ as the objective variable and $\mathrm{NDVI}_{\mathrm{obs}}$ as the explanatory variable. Finally, based on the correction variables sought in formulae (8-10), NDVI correction is performed as shown in Formula (11). In the regression analyses, $p$-values $\leq 0.01$ were considered significant.

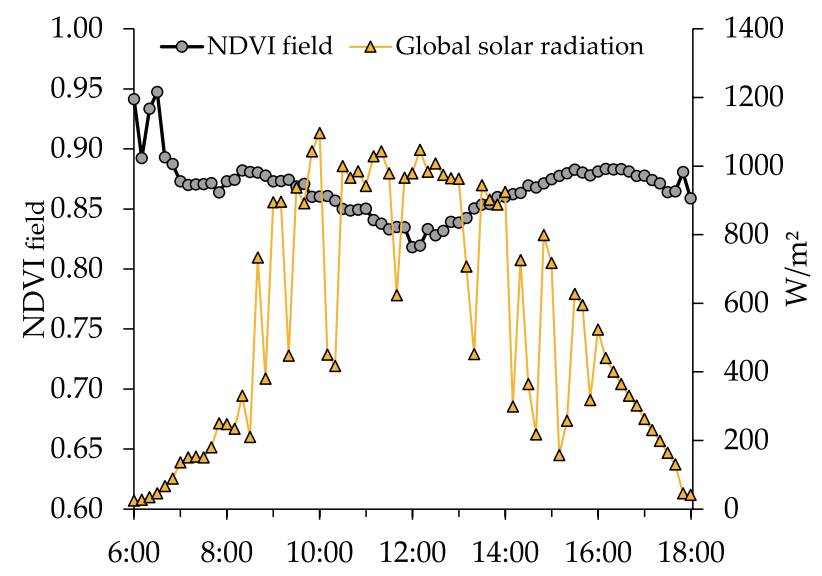

a) Clear day (July $19^{\text {th }}$ )

\section{Results and Discussion}

\subsection{Changes in NDVI with observation time}

Figure 2 shows the changes in $\mathrm{NDVI}_{\text {field }}$ detected by the field sensor on clear and cloudy days. On clear days, we found that $\mathrm{NDVI}_{\text {field }}$ decreased around 12:00, when the solar altitude was high, and thereafter increased. By contrast, on cloudy days $\mathrm{NDVI}_{\text {field }}$ time changes were smaller. These results are similar to those obtained by Ishihara et al. (2015) and other studies. As the solar altitude increases, more incoming light reaches the soil and water beneath the leaves and stalks, as indicated by the increase in observed light reflected from the ground surface and markedly different $\mathrm{NDVI}_{\text {field }}$ values. On cloudy days, on the other hand, there is a greater amount of diffuse solar radiation, and subsequently no major change (with time of day) in the components of light reflected after reaching the ground; this probably accounts for the smaller changes in $\mathrm{NDVI}_{\text {field }}$.

Figure 3 shows the observation-time series of $\mathrm{NDVI}_{\text {field, }}$, as measured by the field sensor, from the early growth period to the heading stage. It can be seen that the $10: 00 \mathrm{NDVI}_{\text {field }}$ rises smoothly. The 8:00, 12:00, and 16:00 $\mathrm{NDVI}_{\text {field }}$ values also rise, but exhibit day-to-day fluctuations. In the correlation analysis between the LOWESS curve and the observed NDVI field shown in Table 1, the coefficient of determination was highest at the 10:00 $\mathrm{NDVI}_{\text {field }}$. This indicates that the time-series change of the 10:00 $\mathrm{NDVI}_{\text {field }}$ was the smoothest. At the experimental field, the solar altitude at 10:00 was between $49.8^{\circ}$ and $64.8^{\circ}$. Optical satellite observations are generally between 10:00 and 11:00. Hashimoto et al. (2019), however, estimated that the best time for drone RS was when the solar altitude was between $25^{\circ}$ and $45^{\circ}$ - based on a radiative transfer model simulationreasoning that the higher the solar altitude, the greater the observed light reflected from the ground surface. However, in June and July (around the time of panicle formation stage-an important period for observing growth and accordingly adjusting fertilization regimes) solar altitude is between $25^{\circ}$ and $45^{\circ}$ at approximately 8:00. During this time window, rice plants are still coated with morning dew, which can cause errors in the spectral measurements (Paul and Pinter, 1986; Maresma et al.,

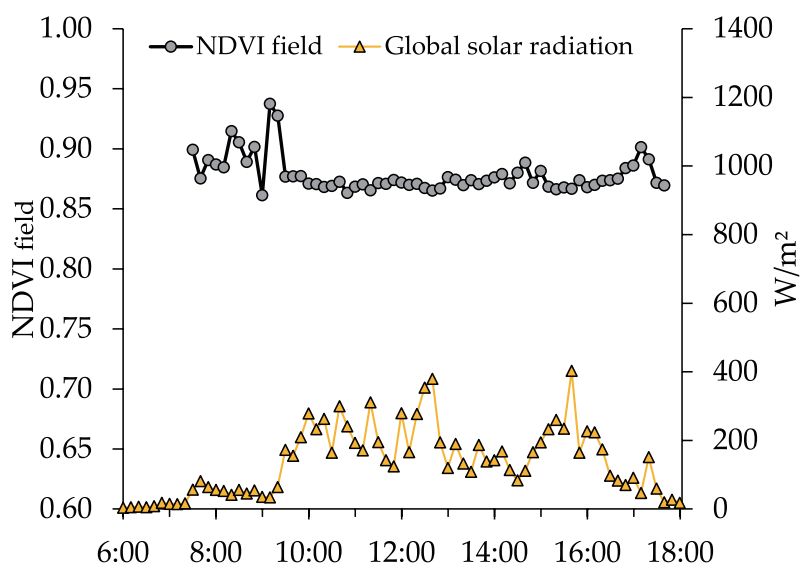

b) Cloudy day (July $18^{\text {th }}$ )

Fig. 2. Changes in NDVI detected by a field sensor on clear and cloudy days. 
2020). Paul and Pinter (1986) reported that when morning dew was present on canopies, morning reflectance in wavelengths shorter than $700 \mathrm{~nm}$ was significantly different from that observed during the afternoon. In the present study, the morning dew evaporated between $7: 40$ and 9:40. Given that this morning dew had generally evaporated by 10:00, we reasoned that the appropriate observation time for low-altitude RS, such as drone RS, is 10:00, the same as satellite RS.

\subsection{Time series of $\mathrm{P} 4 \mathrm{M}$ observational data}

Figure 4 shows the time series of $\mathrm{NDVI}_{\mathrm{P} 4 \mathrm{M}}$ in the six plots situated within the experimental field, as observed on July $22^{\text {nd }}$. Compared to $10: 00$, as the standard observation time, $\mathrm{NDVI}_{\mathrm{P} 4 \mathrm{M}}$ variability fell by $1 \%$ at $12: 00$ in those plots with high $\mathrm{NDVI}_{\mathrm{P} 4 \mathrm{M}}$ values, whereas there was a $6 \%$ decline in plots with low $\mathrm{NDVI}_{\mathrm{P} 4 \mathrm{M}}$ values. This indicates that the measurements for these latter plots were more strongly affected by solar altitude.

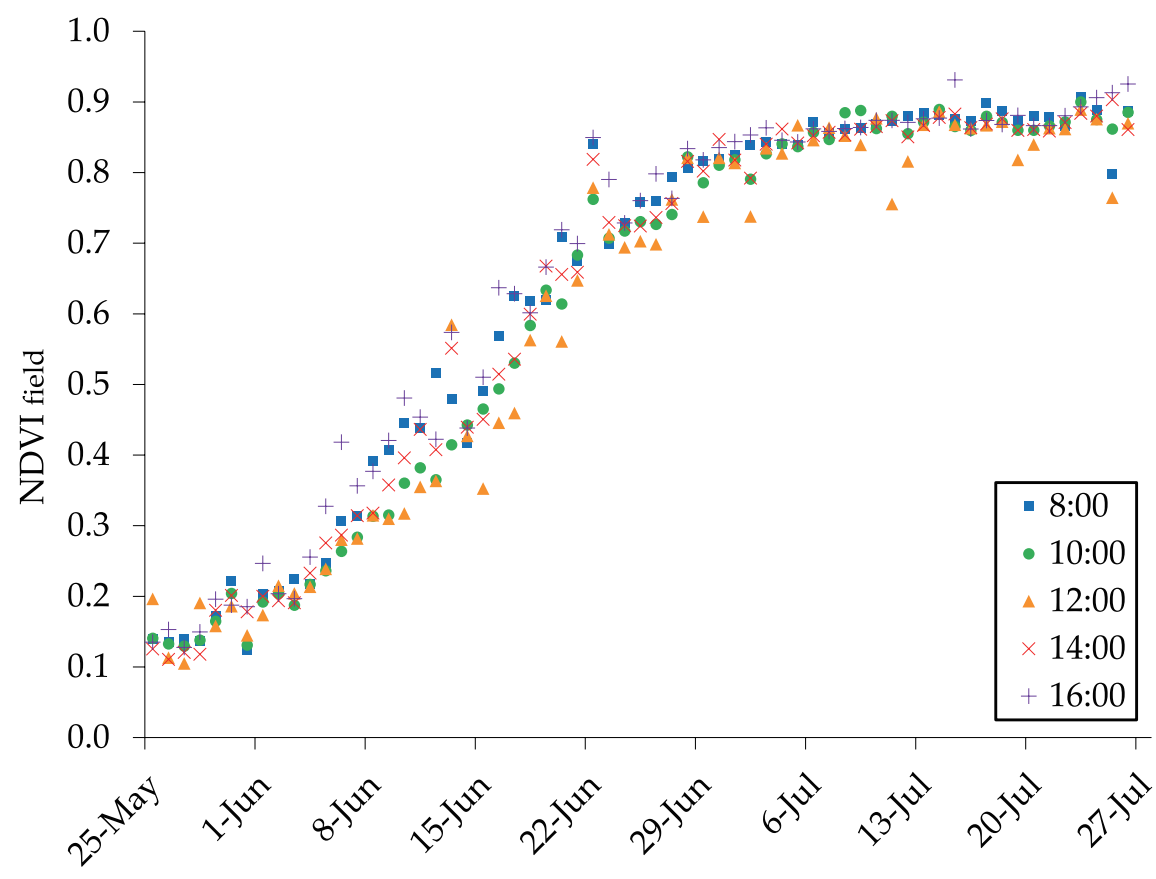

Fig. 3. Time series of NDVI according to observation time, as measured using a field sensor.

Table 1. The coefficient of determination $\left(\mathrm{R}^{2}\right)$ based on a correlation analysis with the LOWESS curve and the observed NDVI.

\begin{tabular}{llllllllll}
\hline & $8: 00$ & $9: 00$ & $10: 00$ & $11: 00$ & $12: 00$ & $13: 00$ & $14: 00$ & $15: 00$ & $16: 00$ \\
\hline $\mathrm{R}^{2}$ & 0.986 & 0.974 & 0.993 & 0.965 & 0.973 & 0.983 & 0.989 & 0.991 & 0.984 \\
\hline
\end{tabular}

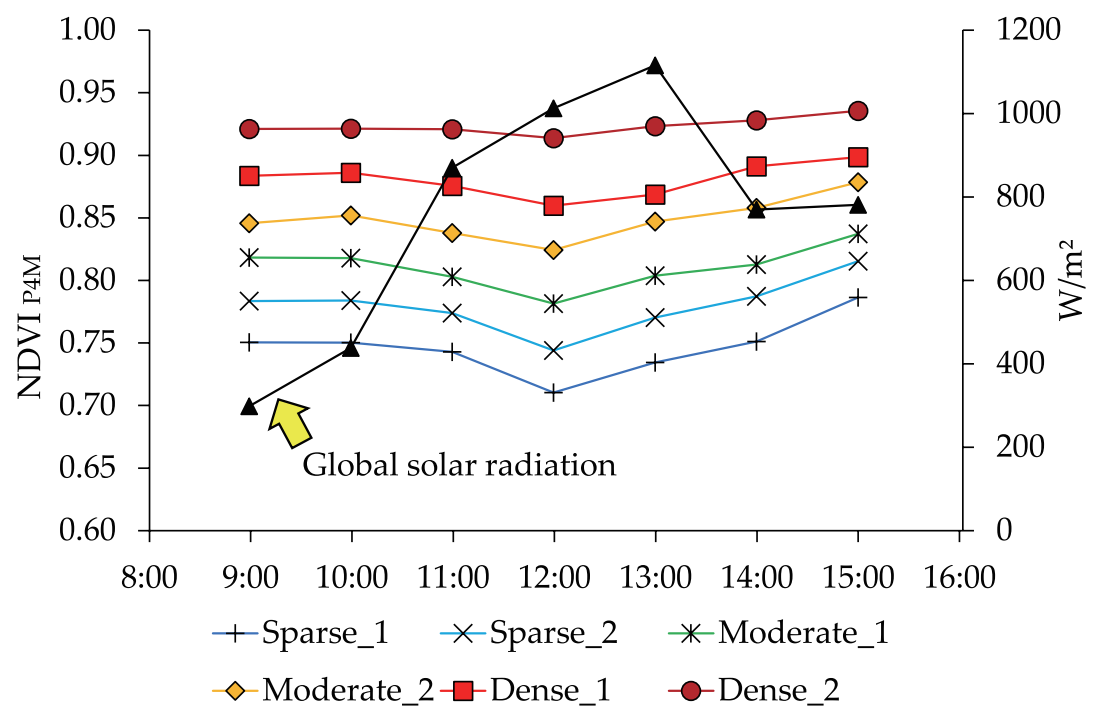

Fig. 4. Time series of NDVI as observed with P4M, July $22^{\text {nd }}$. Black triangles denote the global solar radiation. 
These results are consistent with those obtained by Ishihara et al., (2015), and indicate that higher $\mathrm{NDVI}_{\mathrm{P} 4 \mathrm{M}}$ values are obtained at higher vegetation densities because a smaller fraction of incoming light is reflected after reaching the ground surface. We also found that when correcting $\mathrm{NDVI}_{\mathrm{P} 4 \mathrm{M}}$ values according to sunlight conditions, it was necessary to adjust the amount of correction depending on the $\mathrm{NDVI}_{\mathrm{P} 4 \mathrm{M}}$ values.

\subsection{NDVI correction variables}

Taking 10:00 as an appropriate RS observation time, the assumed standard solar altitude $-H_{o}$ of Formula (8) - was considered to be $60^{\circ}$, the average 10:00 solar altitude during the paddy rice cultivation months, May to September. Figure 5a shows the July $22^{\text {nd }}$ relationship between $C f$-the sunlight condition correction variable-and the $\mathrm{NDVI}_{\mathrm{P} 4 \mathrm{M}}$ variability for each observation time, relative to 10:00. In all of these relationships, $p$-values of 0.01 or lower were considered significant. Furthermore, the gradient (slope of $C f$ against time) was greater for plots with sparse growth, indicating that the vegetation images obtained for these plots were more notably influenced by the effects of sunlight conditions on $\mathrm{NDVI}_{\mathrm{P} 4 \mathrm{M}}$. This slope is the correction variable $S$ in Formula (10).

Figure $5 \mathrm{~b}$ shows the relationship between the correction variable $S$ on July $22^{\text {nd }}$ and 10:00 NDVI $_{\mathrm{P} 4 \mathrm{M}}$. The $p$-values were considered significant at 0.01 or lower. Using the regression equation shown in Fig. 5 b, we obtained values of -0.014 and 0.014 for parameters $a$ and $b$ in Formula (10), respectively. Based on the values obtained up to this point, the $\mathrm{NDVI}_{\mathrm{P} 4 \mathrm{M}}$ correction variables $C f$ and $S$ are as follows (Formulae (12) and (13)).

$$
\begin{aligned}
& C f=\left(H_{D}-60\right) I_{D} / I_{G} \\
& S=-0.014 N D V I_{\text {std }}+0.014
\end{aligned}
$$

\subsection{Corrections of NDVI observed with P4M}

Then, the parameters were applied in Formula (11), the $\mathrm{NDVI}_{\mathrm{P} 4 \mathrm{M}}$ was corrected as follows:

$$
N D V I_{\text {std }}=N D V I_{\text {obs }}(1+0.014 C f) /\left(1+0.014 N D V I_{\text {obs }} C f\right),(14)
$$

Figure 6 shows the pre-correction time series of $\mathrm{NDVI}_{\mathrm{P} 4 \mathrm{M}}$ on July $22^{\text {nd }}$ and August $5^{\text {th }}$ and post-correction by using Formula (14). After these corrections, the $\mathrm{NDVI}_{\mathrm{P} 4 \mathrm{M}}$ changes throughout the day were smaller in all surveyed plots (Table 2). On August $5^{\text {th }}$, observations were made at $10: 30,11: 00,12: 30,13: 00$, $14: 00,15: 00$, and $16: 00$. There were no data for $12: 00$ (the highest solar altitude); therefore, in the time series of $\mathrm{NDVI}_{\mathrm{P} 4 \mathrm{M}}$, the NDVI decline at 12:00 was not clear. The $\mathrm{NDVI}_{\mathrm{P} 4 \mathrm{M}}$ images indicate that the corrected $\mathrm{NDVI}_{\mathrm{P} 4 \mathrm{M}}$ values account for the effects of sunlight conditions (Fig. 7).

It is generally assumed that the most accurate method for NDVI correction uses the radiative transfer model or the bidirectional reflectance distribution function model; however, these models require numerous complex parameters. For the $\mathrm{NDVI}_{\mathrm{P} 4 \mathrm{M}}$ corrections of the present study-given that solar altitude can be calculated from the location coordinates and the observation times - the only necessary on-site observations were the $\mathrm{NDVI}_{\mathrm{P} 4 \mathrm{M}}$ and global solar radiation. Corrections require only few parameters and, given the general reduction in the sunlight-condition effects on $\mathrm{NDVI}_{\mathrm{P} 4 \mathrm{M}}$, this may represent a simple and effective correction method. The results presented herein are based on an empirical formula specifically developed for paddy rice (Koshihikari cultivar), and thus would not directly apply without modification to other vegetation types or cultivars. The amount of the correction corresponds to sunlight conditions and variations in growth; however, further study is required to verify the robustness. On the other hand, if the model parameters were to be adjusted for other vegetation types or cultivars,

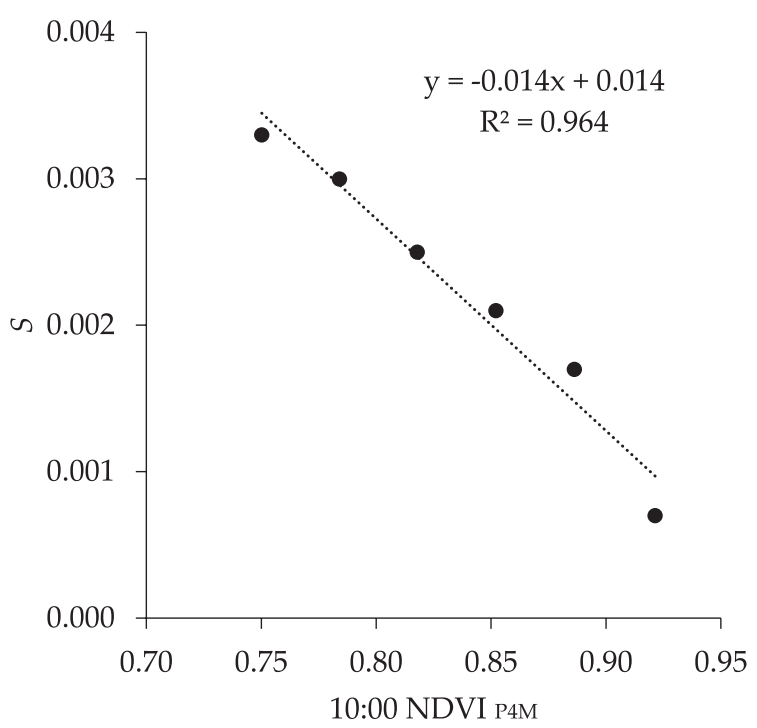

b) 10:00 NDVIP4M and $S$

Fig. 5. The relationship between the rate of NDVI variability and sunlight conditions in the different plots. Dots line denotes the regression line. 


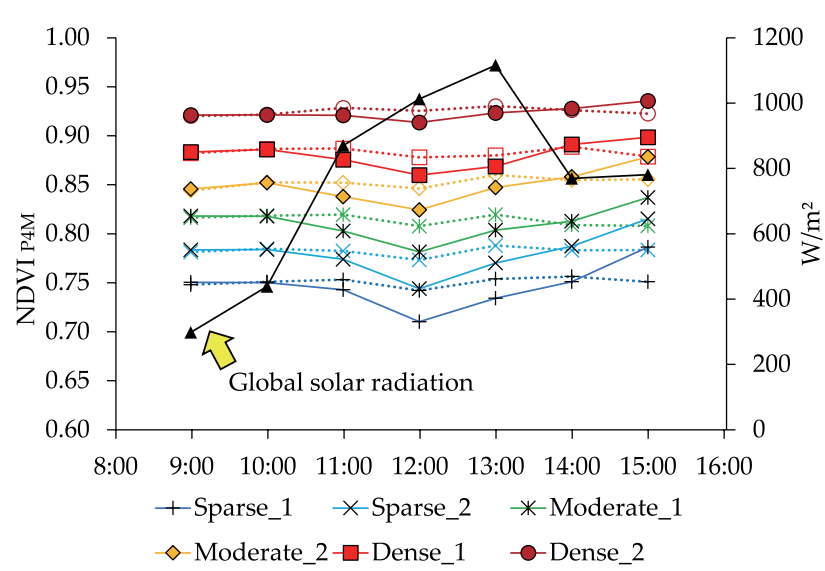

a) July $22^{\text {nd }}$

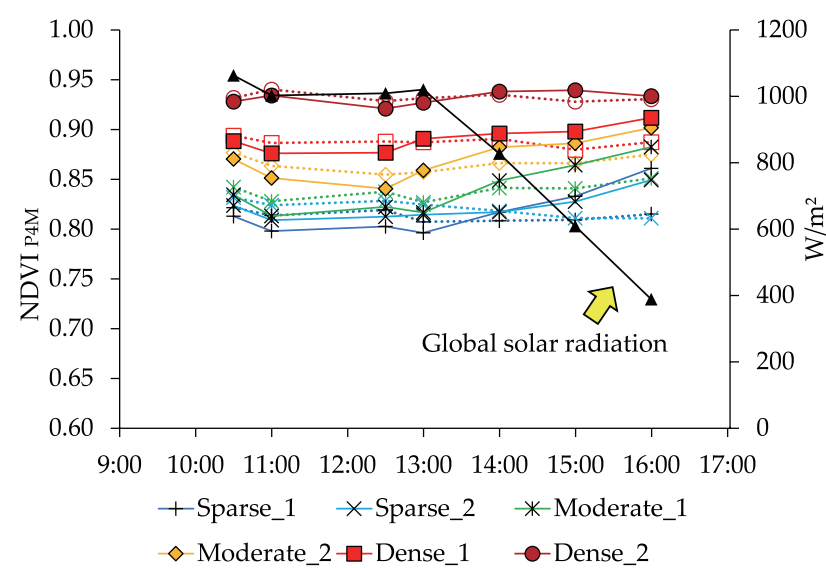

b) August $5^{\text {th }}$

Fig. 6. Post-correction time series of $\mathrm{NDVI}_{\mathrm{P} 4 \mathrm{M}}$. Dots line denotes post-correction $\mathrm{NDVI}_{\mathrm{P} 4 \mathrm{M}}$. Black triangles denote the global solar radiation.

Table 2. The standard deviation of pre- and post-correction NDVI.

\begin{tabular}{ccccc}
\hline Plot & \multicolumn{4}{c}{ Standard deviation } \\
& July $22^{\text {nd }}$ & $(9: 00-15: 00)$ & August $5^{\text {th }}(10: 30-16: 00)$ \\
& Pre-correction & Post-correction & Pre-correction & Post-correction \\
\hline Sparse_1 & 0.021 & 0.004 & 0.021 & 0.005 \\
Sparse_2 & 0.020 & 0.004 & 0.013 & 0.008 \\
Moderate_1 & 0.016 & 0.005 & 0.024 & 0.008 \\
Moderate_2 & 0.016 & 0.005 & 0.020 & 0.008 \\
Dense_1 & 0.012 & 0.004 & 0.012 & 0.004 \\
Dense_2 & 0.006 & 0.003 & 0.006 & 0.004 \\
\hline
\end{tabular}

the procedure of NDVI correction used in this study could be applied to other cultivars.

\section{Conclusion}

In this study, we sought to develop an empirical correction formula that could be used to correct for sunlight conditions in NDVI images of paddy rice captured by drones.

Based on observations using a field sensor installed in a paddy field, the results of our analysis of the appropriate time for observing NDVI in paddy rice showed that the 10:00 $\mathrm{NDVI}_{\text {field }}$ rose smoothly from the early growth period, whereas there were notable day-to-day fluctuations in the rise of the $8: 00,12: 00$, and 16:00 $\mathrm{NDVI}_{\text {field }}$ values. Therefore, we conclude that 10:00 is the most appropriate time for RS observations of paddy rice. Although this time differs from the observation timing of a previously described radiative transfer model, we maintain that the effects of morning dew need to be considered; we established that this dew had mainly evaporated by $10: 00$.

Regarding the time series of drone-observed $\mathrm{NDVI}_{\mathrm{P} 4 \mathrm{M}}$, we found that the effects of differing sunlight were stronger in paddy plots with a lower vegetation density and a subsequently lower $\mathrm{NDVI}_{\mathrm{P} 4 \mathrm{M}}$ value. We speculate that this is attributable to the fact that at higher vegetation densities, a smaller fraction of incoming light reaches the ground surface to be subsequently reflected back. We found also that when correcting $\mathrm{NDVI}_{\mathrm{P} 4 \mathrm{M}}$ values to account for sunlight conditions, it is necessary to adjust the correction parameters depending on the $\mathrm{NDVI}_{\mathrm{P} 4 \mathrm{M}}$ values.

Based on these considerations, we were able to apply corrections to reduce the variations in $\mathrm{NDVI}_{\mathrm{P} 4 \mathrm{M}}$ associated with sunlight conditions. When using the correction method described herein, the only necessary on-site observations were $\mathrm{NDVI}_{\mathrm{P} 4 \mathrm{M}}$ and global solar radiation, thereby making this a simple correction method with very few parameters. Despite its simplicity, it is effective in mitigating the influence of sunlight conditions on $\mathrm{NDVI}_{\mathrm{P} 4 \mathrm{M}}$, and thus has considerable practical utility. However, it should be emphasized that the results obtained in the present study are based on an empirical formula specifically developed for paddy rice; accordingly, caution should be exercised when applying the specified correction parameters to other types of vegetation or cultivars.

\section{Acknowledgments}

This work was supported by JSPS KAKENHI (Grant Number 19J00437, 20H01388), and was conducted as a joint research program of CEReS, Chiba University (2020). 

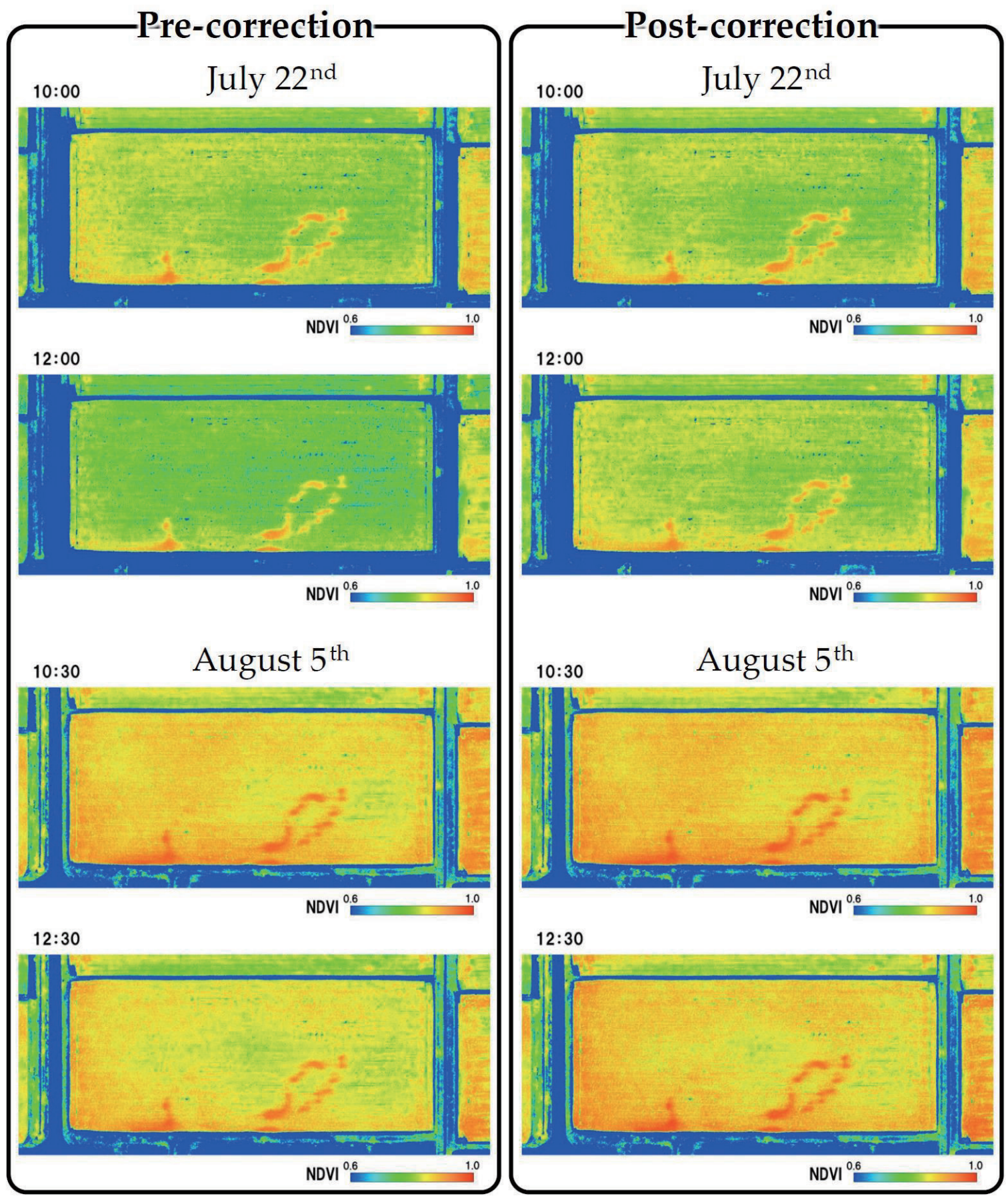

Fig. 7. Pre- and post-correction NDVI images.

\section{References}

Cogliati S, Rossini M, Julitta T et al., 2015: Continuous and long-term measurements of reflectance and sun-induced chlorophyll fluorescence by using novel automated field spectroscopy systems. Remote Sensing of Environment 164, 270-281. DOI: https://doi.org/10.1016/j.rse.2015.03.027

DJI, 2020: https://dl.djicdn.com/downloads/p4-multispectral/ 20200717/P4_Multispectral_Image_Processing_Guide_EN.pdf (accessed on 2020-11-19)

Guan S, Fukami K, Matsunaka H et al., 2019: Assessing correlation of high-resolution NDVI with fertilizer application level and yield of rice and wheat crops

using small UAVs. Remote Sensing 11, 112-131. DOI: https://doi.org/10.3390/rs11020112

Hama A, Hayazaki Y, Mochizuki A et al., 2016: Rice growth monitoring using small UAV and SfM-MVS technique. Journal of Japan Society of Hydrology and Water Resources 29, 44-54. DOI: https://doi.org/10.3178/jjshwr.29.44 (in Japanese with English abstract)

Hama A, Tanaka K, Mochizuki A et al., 2018: Estimating paddy rice plant height and yield using UAV remote sensing and solar radiation. Journal of Japan Society of Hydrology and Water Resources 31, 68-82. DOI: https://doi.org/10.3178/jjshwr.31.68 (in Japanese with English abstract) 
Hama A, Tanaka K, Mochizuki A et al., 2020a: Improving the UAV-based yield estimation of paddy rice by using the solar radiation of geostationary satellite Himawari-8. Hydrological Research Letters 14, 56-61. DOI: https://doi.org/10.3178/hrl.14.56

Hama A, Tanaka K, Mochizuki A et al., 2020b: Estimating the protein concentration in rice grain using UAV imagery together with agroclimatic data. Agronomy 10, 431-445. DOI: https://doi.org/10.3390/agronomy10030431

Hashimoto N, Saito Y, Maki M et al., 2019: Simulation of reflectance and vegetation indices for unmanned aerial vehicle (UAV) monitoring of paddy fields. Remote Sensing 11, 2119-2132. DOI: https://doi.org/10.3390/rs11182119

Hashimoto N, Saito Y, Yamamoto S et al., 2020: Evaluation of machine learning to estimate LAI including solar radiation condition at UAV monitoring in paddy fields. Journal of The Remote Sensing Society of Japan 40, 87-96. (in Japanese with English abstract)

Herrmann I, Bdolach E, Montekyo Y et al., 2020: Assessment of maize yield and phenology by drone-mounted superspectral camera. Precision Agriculture 21, 51-76. DOI: https://doi.org/10.1007/s11119-019-09659-5

Inanuma M, Takeda H, 2002: A study on the characteristics of outside weather factors that affect building indoor environment based on the long-term observation data: Part 3-Estimation of direct and diffuse solar radiation from measured global horizontal solar radiation. Transactions of the Society of Heating, Air-conditioning and Sanitary Engineers of Japan 27, 31-40. DOI: https://doi.org/10.18948/shase.27.87_31 (in Japanese with English abstract)

Inoue Y, Yokoyama M, 2017: Drone-based remote sensing of crops and soils and its application to smart agriculture. Journal of The Remote Sensing Society of Japan 37, 224-235. DOI: https://doi.org/10.11440/rssj.37.224 (in Japanese with English abstract)

IPCC, 2014: AR5 Climate Change 2014: Impacts, Adaptation, and Vulnerability. https://www.ipcc.ch/report/ar5/wg2/ (accessed on 2020-11-19)

Ishihara M, Inoue $\mathrm{Y}$, Ono $\mathrm{K}$ et al., 2015: The impact of sunlight conditions on the consistency of vegetation indices in croplands-Effective usage of vegetation indices from continuous ground-based spectral measurements. Remote Sensing 7, 14079-14098. DOI: https://doi.org/10.3390/rs71014079

Liu HQ, Huete A, 1995: A feedback based modification of the NDVI to minimize canopy background and atmospheric noise. IEEE transactions on geoscience and remote sensing $\mathbf{3 3}$,
457-465. DOI: https://doi.org/10.1109/TGRS.1995.8746027

MAFF, 2016: http://www.e-stat.go.jp/SG1/estat/Pdfdl.do?sinfid= 000031426989 (accessed on 2020-11-19)

MAFF, 2019: https://www.maff.go.jp/j/kanbo/smart/pdf/meguji.pdf (accessed on 2020-11-19)

Maresma A, Chamberlain L, Tagarakis A et al., 2020: Accuracy of NDVI-derived corn yield predictions is impacted by time of sensing. Computers and Electronics in Agriculture 169, 105236.

Matsushita B, Yang W, Chen J et al., 2007: Sensitivity of the enhanced vegetation index (EVI) and normalized difference vegetation index (NDVI) to topographic effects: A case study in high-density cypress forest. Sensors 7, 2636-2651. DOI: https://doi.org/10.3390/s7112636

Mee C, Siva KB, Ahmad HMH, 2017: Detecting and monitoring plant nutrient stress using remote sensing approaches: a review. Asian Journal of Plant Sciences 16, 1-8. DOI: http://dx.doi.org/10.3923/ajps.2017.1.8

Mochizuki A, Hama A, Kusakawa T, 2020: Estimation of rice growth based on proximal remote sensing for topdressing. Abstracts of Meeting of the CSSJ Kanto (in press). (in Japanese with English abstract)

Paul J, Pinter Jr, 1986: Effect of dew on canopy reflectance and temperature. Remote Sensing of Environment 19, 187-205. DOI: https://doi.org/10.1016/0034-4257(86)90071-4

Rahman MM, Lamb DW, Stanley JN, 2015: The impact of solar illumination angle when using active optical sensing of NDVI to infer fAPAR in a pasture canopy. Agricultural and Forest Meteorology 202, 39-43. DOI: https://doi.org/10.1016/j.agrformet.2014.12.001

Saito G, Ishitsuka N, Sakamoto T, 2017: A historical overview of the remote sensing studies on agriculture in Japan. Journal of The Remote Sensing Society of Japan 37, 193-203. DOI: https://doi.org/10.11440/rssj.37.193 (in Japanese with English abstract)

Sakaiya E, Mikami R, Ono H et al., 2016: Implementation of harvest guidance using satellite remote sensing in rice "Seitennohekireki". Abstracts of Meeting of the CSSJ, pp. 169. DOI: https://doi.org/10.14829/jcsproc.243.0_169 (in Japanese with English abstract)

Zhou X, Zheng HB, Xu XQ et al., 2017: Predicting grain yield in rice using multi-temporal vegetation indices from UAV-based multispectral and digital imagery. ISPRS Journal of Photogrammetry and Remote Sensing 130, 246-255. DOI: https://doi.org/10.1016/j.isprsjprs.2017.05.003 